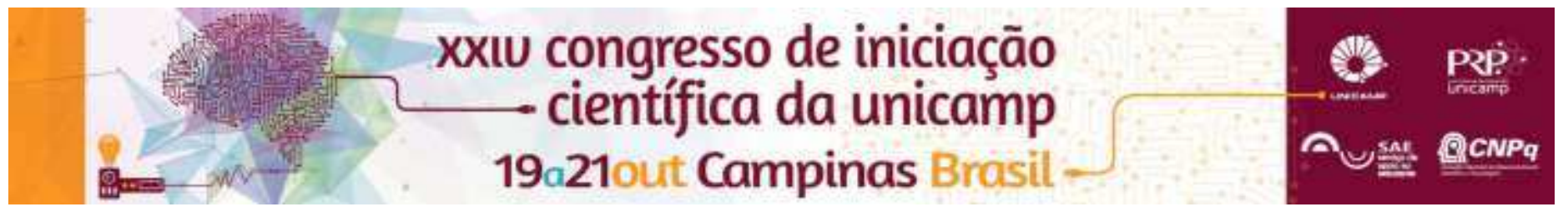

\title{
A dança como promoção da saúde.
}

\author{
Jaqueline Maria da Silva*, Marta Fuentes Rojas.
}

\begin{abstract}
Resumo
A promoção da saude foi definida como processo de capacitação da comunidade para atuar na melhoria da saúde, incluindo uma maior participação nesse processo. A dança é uma atividade física perfeita para se trabalhar com idosos, é uma forme de promoção da saúde, pois sua prática promove bem estar físico, mental e social, além de ser completamnete benéfica a saúde. Este estudo é qualitativo do tipo descritivo e tem como objetivo identificar contribuições da dança na promoção da saúde e na vida dos idosos que frequentam um grupo de dança da terceira idade.
\end{abstract}

Palavras-chave: Promoção da saúde, terceira idade, dança.

\section{Introdução}

Entende-se que a promoção da saúde se dá a partir de boas condições de vida, de trabalho, educação, cultura, lazer e descanso. Ao mesmo tempo, se promove um esforço da comunidade para que se organize e busque alcançar melhoras nas politicas que contribuam para a saúde da população. Assim como, se criam um conjunto de atividades orientadas a propiciar melhores condições de bem-estar (BUSS, 2003).

Em relação à população que esta envelhecendo o aparecimento de modificações fisicas, sociais e psicologicas que afetam o cotidiano das pessoas idosas (GOBBO, 2005), trazem um maior desafio na atenção e cuidados que contribuam para que possam redescubrir possibilidades de viver uma vida com qualidade (BRASIL, 2006).

O aparecimento de grupos sociais e projetos que oferecem atividades para idosos têm facilitado a incorporação de atividade física na terceira idade. Dentro destas atividades a dança torna-se um instrumento que contribui com melhoras tanto fisicas, psiquicas e sociais nesta população (GOBBO,2005; GUIMARÃES, SIMAS; FARIAS, 2003; FILIPETTO e SEVERO, 1999; TODARO, 2002).

Este estudo teve como pergunta principal quais são as contribuições da dança na promoção da saúde e na vida dos idosos que a praticam. O objetivo foi identificar contribuições da dança na promoção da saúde e na vida dos idosos que frequentam um grupo de dança da terceira idade, com a finalidade de conhecer mudanças no cotidiano das pessoas que dela participam.

\section{Resultados e Discussão}

Estudo de caráter qualitativo. Utilizou como instrumento de coleta de dados a entrevista semiestruturada. Participaram 30 idosos, do grupo de dança "Alegria de viver". Foram identificadas quatro categorias de analise: Motivos que levam a praticar; representação da dança na vida, benefícios da dança para a saúde, percepção sobre o antes e o depois da sua participação no grupo de dança.

Os motivos que levam os idosos a a particarem a dança entre eles temos, gostar de dançar desde muito jovem, prescrição médica, estarem se sintindo sozinho e como um lugar para se distrair. Sendo o sentimento de solidão o maior motivo. Conforme a fala de um entrevistado: "por não terem outras ocupações ou afazeres e para se retirar do isolamento de casa, fazer novas amizades, por satisfação pessoal e saúde em todos os sentidos".

Em relação ao que a dança representa os participantes apontam que é um momento que traz prazer, considerada como "uma terapia que alivia a mente", um lugar onde podem se comunicar, se divertir, conhecer amigos.

Os benefícios apontados foram: maior disposição, melhora nas dores físicas, ajuda no emagrecimento e manutenção da forma. Segundo os depoimentos, melhora a autoestima, ficam menos ansiosos e melhora na depressão. Conforme o seguinte depoimento. Igualmente, os benefícios estão mais relacionados com questões emocionais e carências afetivas.

Em relação à percepção sobre antes e depois da sua participação no grupo de dança, os entrevistados afirmam ter tido muita dificuldade para exercer atividades da vida diária, após a dança tiveram melhoras significativas.

\section{Conclusões}

Os grupos de dança são espaços de promoção e prevenção em saúde para a população de idosos. Os beneficios estão relacionados com questões fisicas, sociais e emocionais. Além de trazer prazer, encontro, musica, tranforma-se numa atividade fisica, que promove bem-estar e melhoras no dia-a-dia. Contribui para diminuir a depressão e a solidão. Promove espaço de partilha e descontração.

\section{Agradecimentos}

Ao SAE pelo fornecimento da bolsa.

\section{Referências}

BUSS, P. M. Uma introdução ao conceito de promoção da saúde. IN: CZERESNIA, D. (org). Promoção da saúde: conceitos, reflexões, tendências. Rio de Janeiro, editora Fiocruz, 2003.

GOBBO, D. E. A dança de salão como qualidade de vida para a terceira idade Revista eletrônica de educação física. Uniandrade, 2005.

GUIMARÃES, A.C.A; SIMAS, J.P.N; FARIAS, S.F. Dança como uma

contribuição para a qualidade de vida. Cinergis, Santa Cruz do Sul, v. 4, N.1, p. 29-37, 2003

FILIPETTO, M.C; SEVERO, C. Novas perspectivas: dança e expressão corporal para idosos. Caderno adultos. Santa Maria, n.3, p. 137-138, 1999

TODARO, M. de Á. Dança: uma interação entre o corpo e a alma dos idosos. Dissertação de mestrado - Universidade Estadual de Campinas, faculdade de educação - FE. (2001). 